Corrigendum

\title{
Corrigendum to "How Influential Are Mental Models on Interaction Performance? Exploring the Gap between Users' and Designers' Mental Models through a New Quantitative Method"
}

\author{
Bingjun Xie $(\mathbb{D}$, Jia Zhou $(\mathbb{D}$, and Huilin Wang \\ Department of Industrial Engineering, Chongqing University, Chongqing 400044, China \\ Correspondence should be addressed to Jia Zhou; zhoujia07@gmail.com
}

Received 14 January 2018; Accepted 18 January 2018; Published 20 February 2018

Copyright (C) 2018 Bingjun Xie et al. This is an open access article distributed under the Creative Commons Attribution License, which permits unrestricted use, distribution, and reproduction in any medium, provided the original work is properly cited.

In the article titled "How Influential Are Mental Models on Interaction Performance? Exploring the Gap between Users' and Designers' Mental Models through a New Quantitative Method" [1], there was an error in the seventh paragraph of the subsection "3.7. Quantifying Mental Model Similarity" where the phrase "(see that $\left.b^{i j}=b^{j i}\right)$ " should be removed.

Additionally, in the fifth paragraph of the subsection "4.1. The Influence of Information Structures on Mental Model Similarity" the phrase "than the three structure" should be corrected to "than the tree structure."

\section{References}

[1] B. Xie, J. Zhou, and H. Wang, "How influential are mental models on interaction performance? Exploring the gap between users' and designers' mental models through a new quantitative method," Advances in Human Computer Interaction, vol. 2017, Article ID 3683546, 14 pages, 2017. 


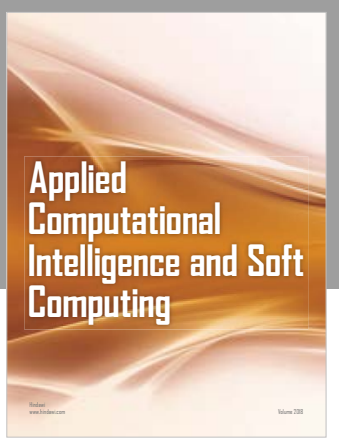

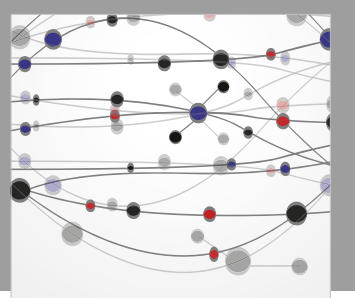

The Scientific World Journal
Submit your manuscripts at

Computing
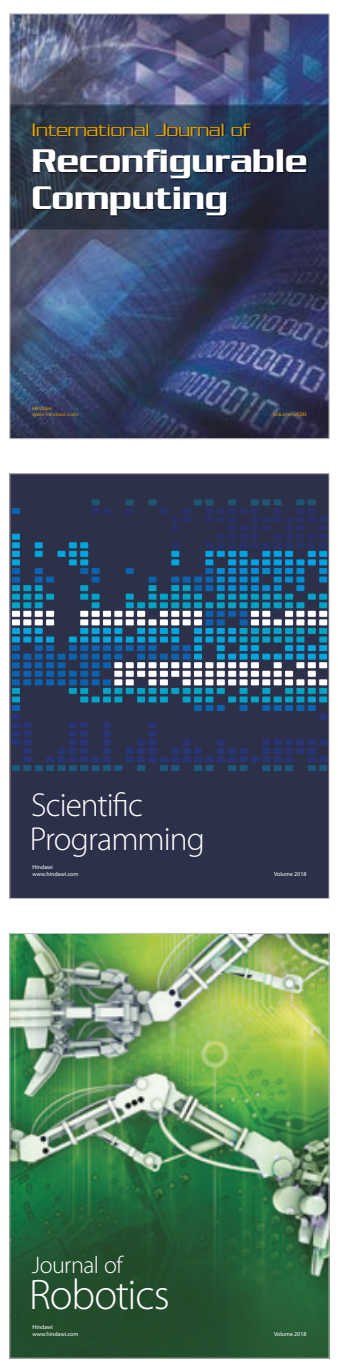

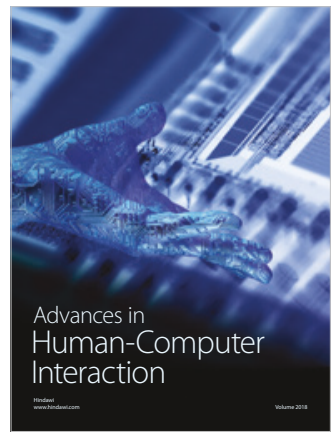

Human-Compute

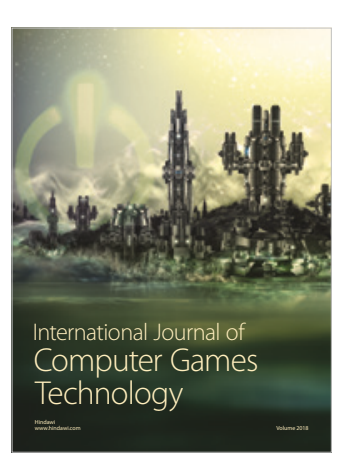

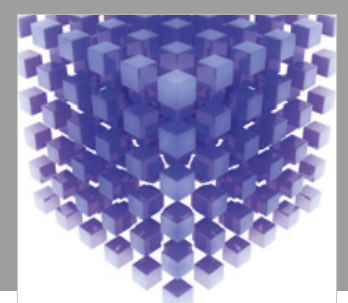

Mathematical Problems in Engineering

\section{Engincering}
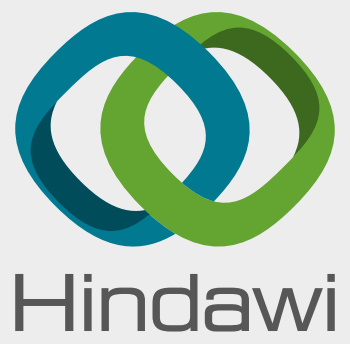

www.hindawi.com
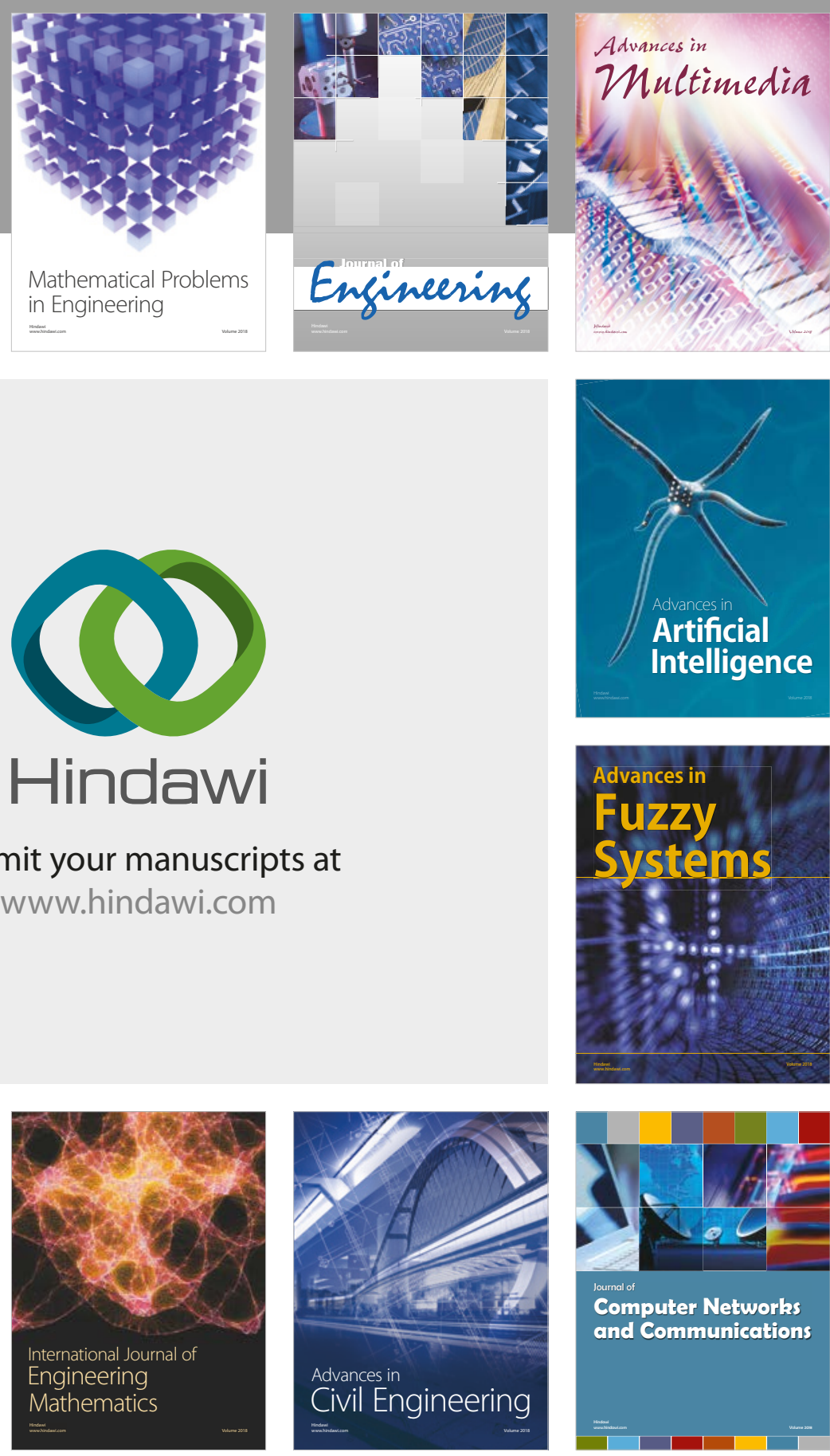

Computer Networks and Communications

Multimedia
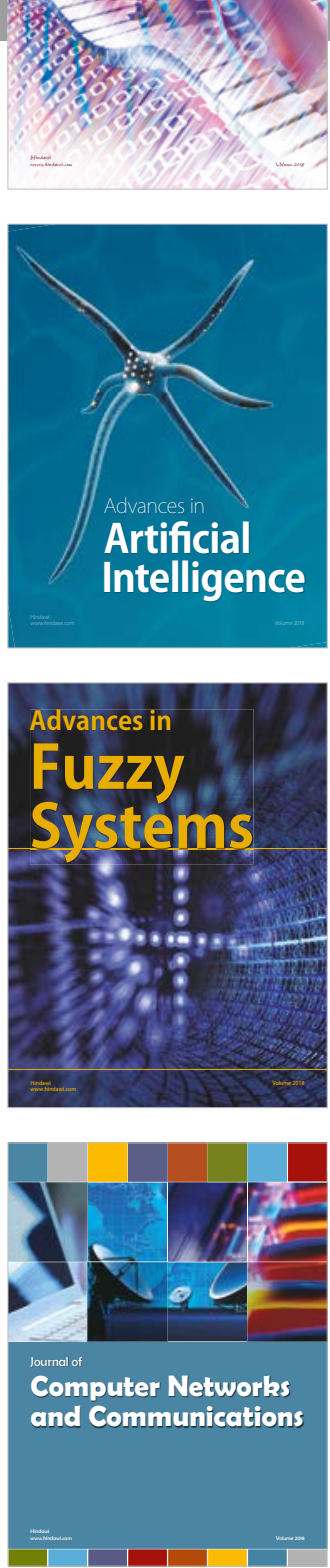

Advances in

Modelling \&

Simulation

in Engineering

interaction

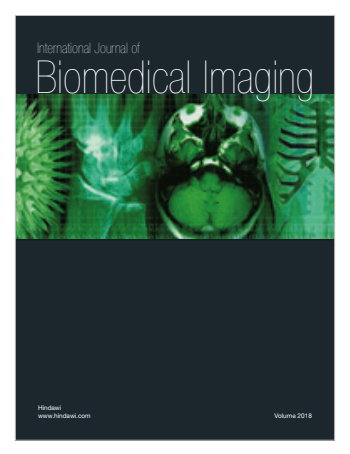

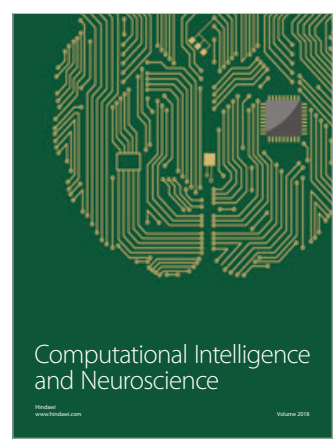

